\title{
Teatralidad y teatro medievales en el occidente peninsular
}

\author{
Pilar Lorenzo Gradín \\ UNIVERSIDAD DE SANTIAGO DE COMPOSTELA
}

Don Enrique de Villena (1384-1434), personaje fundamental en el panorama cultural castellano del primer cuarto del siglo $\mathrm{XV}$, cuando realiza la primera traducción que se hace a una lengua romance de la Eneida, intercala una curiosa glosa de carácter culto a propósito de la palabra theatris, glosa que ha sido analizada pormenorizadamente por el prof. P. Cátedra ${ }^{1}$ y de la que nos interesa recordar su parte final:

E theatro en griego tancto quiere dezir como miramiento, por el mirar que alli se fazia.

Unas palabras magníficas que reproducen, efectivamente, el significado primitivo del théatron griego y que han sido utilizadas como puro pretexto para señalar las conexiones que el teatro mantiene con una actividad de carácter más amplio, con el miramiento, es decir, con el espectáculo. Como han puesto de manifiesto teóricos de la talla de T. Kowzan o M. de Marinis ${ }^{2}$, ambas entidades comparten una serie de características que pueden reducirse principalmente a cuatro:

a) Las dos se basan en la ejecución de un acto que se ofrece a la contemplación del público.

b) En ambas hay copresencia de emisor y destinatario.

c) Se produce simultaneidad de emisión y comunicación, con carácter efímero e irrepetible.

\footnotetext{
' Cfr. P. Cátedra, "Escolios teatrales de Enrique de Villena", Serla philologica Lázaro Carreter. Madrid, 1983, vol. II, pp. 127 y ss.

2 Ver, fundamentalmente, T. KwozAn, Littérature et spectacle, The Hague, 1975; M. DE. MARINIS, Semiótica del teatro. L'analisi testuale dello spettacolo, Milano, 1982.
} 
d) Por último, existe la posibilidad de que el espectáculo, en alguna de sus variantes, incorpore, en cierto grado, lo que K. Young denominó el proceso de impersonation, es decir, la incorporación definitiva del personaje por parte del actor.

Es evidente que en el espectáculo el texto puede no existir, mientras que el "texto teatral" (es decir, la unión de texto literario de carácter dramático y texto espectacular) es una de las "señas de identidad" del género teatro en la Edad Media, ya que es obvio que no nos enfrentamos a una época en la que se cuestione que la actividad que nos ocupa pueda asumir modos de expresión no verbal (como ha sucedido en nuestro siglo con las experiencias llevadas a cabo entre otros por Artaud o Derrida).

Pero hay además otro rasgo en el que conviene insistir de forma especial: la ejecución del texto teatral tiene lugar en un espacio codificado al que se dota de una función sígnica: por eso Féral afirma que "le passage du littéraire au théâtral est toujours, et prioritairement, un travail spatial"'. Habida cuenta de que durante el Medioevo no existían edificios específicos que acogieran tal práctica (ya que los antiguos teatros romanos eran el signo evidente tanto de la cultura profana como de la institucionalización de un género que había llegado en los últimos años del Imperio a una etapa de degeneración, cargada de exageraciones y abusos, entre los que ocupaban un lugar preeminente para la cultura oficial de nuestro período los martirios de los cristianos). ésta se refugió en espacios preexistentes (la iglesia, el claustro, el atrio, la plaza, el salón de un palacio ducal, etc) espacios que, durante el tiempo que duraba la representación, se desprendían de su función primaria gracias a la presencia de un actor que convertía en espacio simbólico el espacio real en el que se movía.

Las premisas teóricas que han guiado esta breve y rápida introducción han sido las utilizadas para establecer el número de piezas teatrales y de manifestaciones espectaculares que hemos incluido en las tradiciones medievales del reino de Portugal y del condado del viejo Finis terrae latino.

\section{TEATRO}

Aunque siempre es difícil marcar un término a quo para cualquier género literario, para el teatro de la zona geográfica estudiada la tarea es mucho más

"J. Feral, "La théâtralité. Recherche sur la spécificité du langage thêâtral", Poétique, LXXV (1988). p. 349. 
ardua a causa de la escasez de documentación (directa o indirecta) transmitida, por lo que el punto de partida se revela un tanto artificial.

Mientras que en el Este peninsular el conocido como drama litúrgico (es decir, aquella forma embrionaria de teatro, escrita en latín, de tema religioso y, tal y como indica el modificador, en estrecha relación con la liturgia) se desarrolla de forma paralela a lo que ocurre en el resto del contexto europeo, continuándose la tradición de forma ininterrumpida entre los siglos XII a XVI, en el resto de la Península el género nunca llegó a prender.

La primera manifestación que se documenta de esa actividad en el Occidente peninsular procede de Santiago de Compostela y es una Visitatio Sepulchri, ejecutada, como se sabe, al final del oficio de maitines. El manuscrito sólo ha transmitido un texto literario de factura muy simple (lo que los especialistas conocen como Visitatio $I^{4}$, compuesto, como han demostrado $\mathrm{H}$. Anglès y el P. Donovan, bajo el influjo del monasterio de Vich, con el que la sede gallega mantuvo intercambios de códices musicados 5 . Podemos imaginar cómo era la ejecución de dicho testimonio, no sólo utilizando un criterio de pertinencia externa como es el sincrónico, es decir, recurriendo a la comparación con textos pertenecientes al mismo ciclo y de la misma época, sino también porque ha sido transmitido sin apenas cambios en dos versiones del siglo XV - la compostelana fechada en 1450 y la lisboeta de 1497-, insertas en un breviario que perteneció a un canónigo de la catedral de Santiago, el conocido canónigo Miranda ${ }^{6}$ (es difícil precisar si se trata de Pedro o Luis de Miranda, ya que ambos aparecen mencionados en documentos de los años 1481 y $1483)^{7}$. El texto transmitido por el breviario conservado en la Catedral de Santiago es el siguiente:

\section{RESPONSORIUM}

\section{Dum transisset sabbatum (...)}

${ }^{4}$ El texto puede consultarse en W. LIPPHARD, Lateinische Osterfeiern und Osterspiele, Berlín, 1975-1981, vol. I, n 452.

5 Cfr. H. ANGlès, La Música a Catalunya fins al segle XIII, Barcelona, 1935, pp. 259-260; R. Donovan, The Liturgical Drama in Medieval Spain. Toronto, 1958, p. 56; Idem, "Two Celebrated Centers of Medieval Liturgical Drama: Fleury and Ripoll", en The Medieval Drama and Its Claudelian Revival, Washington, 1970, pp. 41-51.

${ }^{h}$ Hasta hace poco se creía que el breviario compostelano fuera confeccionado por uno de los Miranda, pero un análisis detallado de los escudos que figuran en las páginas iniciales revelan que éstos fueron rehechos, perteneciendo el escudo primitivo al linaje de los Luna. Este dato hace suponer que el valiosísimo breviario perteneció al arzobispo don Rodrigo Luna, sobrino del famoso favorito de don Juan II, don Álvaro de Luna (Para éste y otros datos, consúltese J. M. ${ }^{a}$ Díaz Fernández, "El breviario de Miranda", en AA.VV., Santiago camiño de Europa. Culto e cultura na peregrinación a Compostela, Santiago de Compostela, 1993, p. 339).

${ }^{7}$ Cfr. los datos proporcionados por Lópeź Ferreiro, Historia de la Santa A. M. Iglesia de Santiago de Compostela, 1904, vol. VII, pp. 347 y ss. 
Hic TRES PUERI in similitudine MULIERUM induti vestimentis candidis peragant de choro usque ad altare UNUS post UNUM blande cantantes hanc Antiphonam:

Ubi est Christus, meus Dominus et filius excelsi?

Eamus videre sepulcrum.

ALIUS PUER stans retro altare in similitudine ANGELI indutus vestimentis candidis; dicat hanc Antiphonam:

Quem queritis in sepulcro, o Christicole?

Et MULIERES respondeant blande Antiphonam:

Jesum Nazarenum crucifixum, o celicole.

Et ANGELUS Antiphonam:

Non est hic, surrexit, sicut predixerat;

ite nunciate, quia surrexit.

Et MULIERES eodem modo, quo ante venerunt, dicant alta voce cantantes redeundo Antiphonam:

Alleluia. Ad sepulcrum residens

Angelus nunciat resurrexisse Christum.

Te Deum laudamus (...)

(Lipphard, $n^{\circ} 453$ )

La única diferencia constatable entre la versión de Santiago y la impresa en Lisboa es que esta última incorpora, además del Versus Et valde mane tua y de las Prosas Ut venientes Gloria y Alta concinite Christo voce, la conocida Prosa del Alleluia Dic nobis, Maria (que figura antes del Te Deum final), en la que el coro (que representa a los apóstoles) pregunta a María Magdalena sobre el episodio en el que el propio Cristo se le aparece en figura de hortolanus (Ioan. 20, 14-17). Es éste un tránsito brusco que implica el conocimiento por parte del público de ciertos pasajes evangélicos (por ej. la visita al sepulcro de Pedro y Juan; los ángeles que dan la noticia de la Resurrección a Magdalena), pero la omisión es una técnica bastante común en estas piezas, en las que el desenlace es conocido y en las que se acepta una convención que asienta sus bases en la competencia ideológica del público, conocedor de la mitología sobre la que está basada la trama que está contemplando. Pero lo que realmente no puede dejar de ser sorprendente es la poca vitalidad que ofrecen las formas comentadas, que mantienen un mismo texto base a pesar de haber transcurrido entre la primera pieza y las últimas tres siglos. 
Como se observa en las didascalias reproducidas aquí arriba, el sencillo drama litúrgico compostelano está totalmente inmerso en el contexto litúrgico: el "attrezzo" no ofrece ninguna complejidad ni refinamiento, ya que tanto los chicos que representan a las Marías como los ángeles van vestidos con túnicas blancas, albas o dalmáticas (vestimentis candidis, amictis candidis); no se hace ni una sola referencia al lenguaje gestual y el movimiento es más bien procesional, transcurriendo la acción entre el altar principal y el coro (peragant de choro usque ad altare / redeant ad chorum). Como se recordará, ambos espacios escénicos ofrecían un significado simbólico, en el que insisten la práctica totalidad de los comentaristas medievales, y según el cual el primero era identificado con el sepulcro, mientras que el coro simbolizaba a la comunidad de fieles a los que se destinaba la buena nueva ${ }^{8}$.

Si los textos gallegos se comparan con otras Visitationes europeas de los siglos XII y XIII, no queda lugar a dudas de lo limitada y rudimentaria que es su capacidad mimética o teatral. A fin de aclarar este aspecto, se ha seleccionado un fragmento de uno de los textos más logrados, la conocida Visitatio de Fleury-sur-Loire:

"Post hec Maria Magdalene, relictis duabus aliis, accedat ad Sepulcrum, in quod sepe aspicie[n]s dicat:

Heu dolor, heu quam dira doloris angustia,

Quod dilecti sum orbata magistri presencia!

Heu, quis corpus tam dilectum sustulit e tumulo?

Deinde pergat velo[citer] ad illos qui in similtu[di]ne Petri et Iohannis pr[e]stare debent ere[cti], stansque ante eos quasi trist[is] dicat:

Tulerunt Dominum meum, et nescio ubi posuerunt eum,

Et monumentum vacuum est inventum,

Et sudarium cum sindone intus est repositum.

Illi autem, hec audientes, vel[ociter] pergant ad Sepulcrum acsi curre[ntes], sed iunior, scilicet Iohannes, preveniens st[et] extra Sepulcrum; senior vero, scilicet Pe[trus], sequens eum, statim intret; postquam et Ioh[annes in]tret. Cum inde exierint, Iohannes quasi [ad]mirans dicat:

Miranda sunt que vidimus!

An furtim sublatus est Dominus? $?^{9}$

* Ver B. D. Berger, Le Drame liturgique de Pâques. Liturgie et Théâtre, París, 1976, pp. 261 y ss.; L. AlLteri, Teatro e spettacolo nel Medioevo, Bari, 1988, pp. 221-222.

${ }^{y}$ El texto procede de la edición de K. Young, The Drama of the Medieval Church, Oxford, 1933, vol. I, pp. 394-395. 
A pesar de que los protagonistas son diáconos (y hombres con arreglo a la tradición, ya que la cultura cristiana que conocía la degradación a la que habían llegado las mujeres que practicaban el mimo en los últimos tiempos del Imperio romano, no podía considerar a la actriz más que -en palabras de L. Allegri- "il risultato di due principi negativi - attore-donna-che si moltiplicano a vicenda") ${ }^{10}$, han desaparecido los elementos rituales y hay un intento espectacular más articulado tanto en lo que se refiere a la vestimenta y accesorios, como al gesto: los actores van vestidos con arreglo al papel que desempeñan, sus movimientos y gestos se adaptan a la acción que interpretan (cfr. la magnífica descripción de la llegada de Juan y Pedro al Sepulcro) e incluso parece que el lugar central de la acción, el Monumentum, podría ya no ser el altar, sino una construcción que acentuaría el carácter imitativo de la obra. Pero hay algo más. Mientras que en las versiones de la Visitatio de Santiago, el receptor del espectáculo es el coro de monjes, en la de Fleury se hace referencia por tres veces (en concreto en la intervención de María Magdalena tras el encuentro con Cristo; y en el anuncio de la Resurrección y la muestra de la sábana Santa a los fieles en dos pasajes de las Santas mujeres) al público (designado con las voces populum o plebem), lo que implica el paso de lo que Allegri ha denominado "teatralidad difusa" " al teatro en sentido pleno, proceso que conlleva un importante cambio de función en la ceremonia: la separación institucional entre quien actúa y quien ve.

Pero vale la pena recordar que no es totalmente casual que sea precisamente en Fleury donde se encuentre una pieza con una estructura y un tono dramático tan desarrollados. Si hacemos memoria, el primer texto que documenta el desplazamiento del tropo del Quem quaeritis al oficio de maitines, donde aquel canto encontrará una libertad litúrgica que marcará la evolución del rito al drama, es la Regularis Concordia del arzobispo de Winchester (965-975), quien precisa que lo que allí describe no es más que la imitación de lo que se realiza, precisamente, en la abadía continental de Flcury-sur-Loire. Si hacemos las oportunas cuentas, percibimos que la obra francesa gozaba con una tradición de más de dos siglos a sus espaldas, una situación bien distinta a la de Compostela y a la de todo el Occidente peninsular.

Como se recordará, el drama litúrgico se desarrolla en toda Europa gracias a la puesta en marcha del rito romano impulsado por el Papa Adriano I (+795) y por el emperador Carlomagno. Intímamente ligados a él (por las carencias que éste tuvo en un principio y por el proceso de enriquecimiento que exigía el reto de una renovación monástica), aparecen, a mediados del siglo IX, los primeros ejemplares de lo que se conoce como tropos, es decir, los cantos interpolados o añadidos a un canto litúrgico oficial de la misa o a un canto del Oficio, que van a extenderse y practicarse en todas aquellas

14" AlLEGRI, Teatro e spettacolo, p. 95. A este propósito, cabe recordar que la participación de las mujeres en los dramas litúrgicos se documenta tan sólo en monasterios femeninos y en una época tardía (finales del siglo XIII).

"Idem lbidem, p. 34. 
sedes en las que triunfe la autoridad de Roma ${ }^{12}$. Pero ese rito llegará al Occidente peninsular con un retraso de casi tres siglos, ya que en la zona de influencia castellana será promulgado por el rey Alfonso VI en el Concilio de Burgos del año 1080, en el que quedará abolida definitivamente la práctica local del rito mozárabe. Las diócesis de Braga y Coimbra ${ }^{13}$, que ocupaban todo el territorio del condado portugués (ya que recuérdese que éste sólo se emancipa de Castilla y se constituye en reino independiente en el año 1139 con Afonso Henriques), fueron los últimos reductos de los territorios feudales del rey castellano que se resistieron al cambio de liturgia. En Coimbra sólo será acogido tras la muerte del gobernador mozárabe Sisenando en 1091, quien hasta aquel momento gozaba del favor de nombrar a los obispos sin la clara oposición del rey castellano, que se veía obligado a pagar de este modo los favores prestados a su padre, Fernando I, por el "alguacil" en la Reconquista de la ciudad y territorios vecinos. Con el nombramiento de un nuevo obispo, Cresconio de Tuy, el rito romano se introduce al sur del Duero a inicios del año 1092.

En Braga la política eclesiástica también tuvo sus consecuencias respecto a la reforma litúrgica. El obispo Pedro, que no era capaz de conseguir que su metrópolis lograra la calidad de arzobispado, intrigó con el antipapa Clemente III (que se instaló en Roma con el apoyo del emperador alemán Enrique IV) que le otorgó el palio en el año 1090. Sus ansias de poder le salieron caras, ya que fue inmediatamente depuesto por el primado Bernardo de Toledo, que, en 1096, nombró para el cargo a un monje cluniacense del monasterio de Moissac, Geraldo, que sometió la diócesis a la disciplina de Roma, recibiendo inmediatamente el título de arzobispo.

Así pues, el rito romano llega al Occidente peninsular tarde y de la mano de los cluniacenses, quienes habían manifestado ya desde la puesta en práctica del nuevo ritual una oposición tajante a todos aquellos textos que no tuvieran un carácter bíblico (por oposición a Benito de Aniano). Es esta circunstancia la que explica la ausencia de cultivo de tropos en la zona, ya que, realmente, el recogido en un Psalterium del siglo XIV, procedente del monasterio de Santa Cruz de Coimbra y entonado durante el oficio de laudes la noche de Navidad ${ }^{14}$, no es más que la excepción que confirma la regla. Y es de tanto calibre esta excepción que debe recordarse que el mencionado monasterio se regía por la regla de San Agustín y mantuvo siempre frente a Cluny actitudes independientes y, en algunos casos, incluso hostiles.

12 A este propósito véase la información proporcionada por E. CASTRo, Tropos y troparios hispánicos, Santiago de Compostela, 1991, pp. 53 y ss.

${ }^{13}$ Como se sabe. hasta el siglo IX, el mapa eclesiástico de la Península estaba integrado por cinco provincias: Bética (Sevilla), Lusitania (Mérida), Gałicia (Braga), Tarraconense (Tarragona) y Cartaginense (Toledo).

14 Cfr. S. Corbin, Essai sur la musique réligieuse portugaise au Moyen-Age (1100-1385), París, 1952, p. 124. 
La rigidez de rito impuesta por la orden cluniacense tuvo que tener pésimas consecuencias en el florecimiento del teatro religioso, ya que, aunque hoy en día la tesis que considera fundamental el cultivo de los tropos en el nacimiento del teatro está superada, no es menos cierto que cuando uno lanza una ojeada al resto de las manifestaciones del contexto europeo, liturgia y teatralidad se encuentran estrechamente unidas. Al no existir formas embrionarias que pudieran ser desarrolladas en otros contextos litúrgicos, el Occidente peninsular no tuvo capacidad para recorrer el camino que marca el tránsito del rito al drama.

\section{TEATRALIDAD}

Desde que R. Barthes introdujo el término teatralidad en un ensayo dedicado al análisis de cuatro proyectos teatrales de Baudelaire, éste no ha dejado de ser utilizado por los estudiosos ( $y$, a veces, quizás de forma un tanto abusiva). Decía el crítico francés que la teatralidad:

"Es el teatro sin el texto, es un espesor de signos y sensaciones que se edifica en la escena a partir del argumento escrito, esa especie de percepción ecuménica de los artificios sensuales, gestos, tonos, distancias, sustancias, luces, que sumerge el texto bajo la plenitud de su lenguaje exterior"15.

Para Barthes, por tanto, esa condición sólo se da en la escena teatral. Postura bien diversa de la de P. Zumthor ${ }^{16}$ que habla de la teatralidad "quasi-omnipresente" de la literatura medieval, habida cuenta de que en la época el fenómeno literario es en su mayoría de expresión oral y se sirve de una serie de elementos que exigen una cierta "performance" que se ofrece al espectador. Estamos en este caso ante la teatralidad del juglar, concebido como el profesional itinerante especializado en la ejecución de literatura variada (como apuntan los célebres ensenhamens de Guiraut Cabrera o Guiraut de Calanson). Pero hay que precisar que ese juglar no transforma el espacio y el tiempo, no transgrede lo cotidiano, no semiotiza los signos y, finalmente, no deja pasar lo imaginario a través de su cuerpo (utilizando una terminología de tipo brechtiano podría decirse que no incorpora al personaje).

A continuación el término teatralidad será empleado en el sentido que le ha dado J. Féral en su artículo publicado en el año 88 en la revista Poétique ${ }^{17}$,

\footnotetext{
1.5 R. Barthes, Ensayos críticos, París, 1964 (traducción española, Barcelona, 1983, p. 50).

16 Véase P. Zumthor, La lettre et la voix. De la "littérature" médiévale, París, 1987, pp. 267 y ss.

${ }^{17}$ Féral, "La théâtralité. Recherche sur la spécificité du langage théâtral".
} 
y en el que el concepto está cercano al de espectacularidad. El término se conecta con una dinámica visual, con el miramiento de don Enrique de Villena, y se refiere a todos aquellos fenómenos que atraen la atención del espectador hacia otro lugar, en el que él percibe, con la distancia que proporciona una mirada externa, un espacio en el que las normas y las leyes no son las de la cotidianeidad y en el que se establece un cierto grado de fícción ${ }^{18}$.

El primer documento que corrobora la existencia de la teatralidad en el Occidente peninsular se remonta al mes de agosto de 1193, fecha en la que el rey portugués Sancho I (1154-1211) dona unas tierras en la localidad de Canelas a dos hermanos juglares: Bonamis y Acompaniado. En la confirmación de la mencionada donación, ambos se comprometen a recompensar al monarca con la ejecución de un arrimidilum, es decir, un arremedilho: "Nos mimi supranominati debemus Domino nostro Regi pro roboratione unum arremedillum" 19 . Aunque la procedencia del término no plantea problemas, ya que es un deverbal de *re+imitare, 'imitar', no se puede decir lo mismo de su contenido, ya que no se nos dice nada acerca de las características que tal forma de espectáculo tenía. Desde que en el siglo XVIII el lexicólogo portugués Fr. Joaquim de Santa Rosa de Viterbo dio como equivalentes del substantivo los términos 'entremés', 'farsa', 'comedia' o 'representación jocosa', buena parte de la crítica (desde T. Braga a la célebre C. Michäelis o, más recientemente, L. F. Rebelo ${ }^{20}$ consideró que aquel pequeño texto de la cancillería real documentaba la primera manifestación del teatro portugués. Sin embargo, si uno analiza el significado que el término tiene en otros contextos, esa interpretación se muestra un tanto audaz y forzáda. El verbo remedar es utilizado en la famosa Declaratio con la que Alfonso $\mathrm{X}$ de Castilla responde en 1275 al trovador occitano Guiraut Riquier, precisamente a propósito de las denominaciones de 'juglar' y 'trovador' en la tradición peninsular, y en la que se dice: et als contrafazens/ditz hom 'remedadors' ('y a los que imitan, se les llama 'remedadores') ${ }^{21}$. Asimismo, en una de las Cantigas de Santa María, concretamente en la 293 un osado juglar de Lombardía será castigado por remedillo fazer de la propia Virgen:

Esto foi en Lonbardia dun jograr remedador que atan ben remedava, que avian en sabor todos quantos lo viian, e davan-lle con amor panos e selas e freos e outro muito bon don.

Par Deus, muit'é gran dereito de prender grand'ocajon...

\footnotetext{
${ }^{18}$ Idem Ibídem, pp. 350 y $358-359$.

${ }^{19}$ Cfr. Fr. Joaquim de Santa Rosa de Viterbo, Elucidário das palavras, termos e frases que em Portugal antigamente se usaram..., edición de M. Fiúza, Lisboa, 1980, vol. I, p. 594b.

${ }_{20}$ Puede verse un resumen de la cuestión en J. Oliverra Barata, História do Teatro Português, Lisboa, pp. 66 y ss.

${ }_{21}^{2}$ El texto procede de la edición realizada por V. Bertolucci, "La Supplica di Guiraut Riquier e la Risposta di Alfonso X di Castiglia", Studi mediolatini e volgari, XIV (1966), pp. 9-135.
} 
E el con sabor daquesto ja mais non fazia al senon remedar a todos, uus ben e outros mal; mas o dem', a que criia de consello, fez-ll'atal remedillo fazer, onde recebeu mui gran lijon. Par Deus, muit'é gran dereito de prender grand'ocajon...

E assi foi que un dia per hua porta entrar da vila foi, mui ben feita, e viu sobr'ela estar hua mui bela omagen da Virgen que non á par, teendo seu Fill'en braço. Mas non fez y oraçon,

Par Deus, muit'é gran dereito de prender grand'ocajon... ${ }^{22}$

Los testimonios traídos a colación parecen ser lo suficientemente explícitos y dan pie para pensar que el arrimidilum era una actividad lúdica de carácter cortesano, una técnica espectacular de juglares en la que se intentaba imitar a personas o animales mediante el gesto, la inflexión de la voz, la forma de andar, etc.

Desde el siglo XIV hasta el XVII se suceden en Portugal una serie de prohibiciones eclesiásticas que advierten una y otra vez del peligro que encierran los jogos desonestos y el homo pictus, denigrado por Juan de Salisbury por aquello de que homo pictus non est homo (y, seguramente, es este prejuicio el que mantiene el obispo de Burgos Alfonso de Cartagena en la primera mitad del siglo XV, cuando, a propósito de los momos, dice que "aunque de dentro dél esté onestat e maduretat e gravedat entera, pero escandalízase quien ve fijodalgos de estado con visajes agenos" ${ }^{23}$ ). Como reza el acta del sínodo celebrado en Oporto en 1477, se insiste, sin embargo, en que se pueden realizar, "boas e devotas representaçoes, como a do presépio, a dos reis magos ou outras da mesma natureza" 24 . Conviene tomar con cierta cautela los datos que se extraen de estos sínodos provinciales, ya que, realmente, ofrecen idéntica formulación en la mayoría de los países europeos, lo que podría indicar, como demostró $\mathrm{H}$. López Morales para la tan traída y llevada ley de la Primera Partida ${ }^{25}$, que no son más que la adaptación de decretos y disposiciones papales que las autoridades locales recogían sin pestañear, aunque no siempre respondieran de manera fehaciente a la realidad circundante. La valoración de ese material constituye un problema de particular importancia para el estudioso, ya que, aunque no ha faltado quien las erigiera en la prueba a contrario de la vitalidad del teatro, al no facilitarse ni siquiera el incipit de un verso o alguna breve referencia espectacular, es difícil valorar el peso que las representaciones ahí referidas desempeñaron en la formación de la tradición teatral del Occidente peninsular.

22 W. Mettmann, Cantigas de Santa María, Madrid, 1986, vol. III, $\mathrm{n}^{\circ} 293$.

${ }^{23}$ Cfr. E. Asensio, "De los momos cortesanos a los autos caballerescos de Gil Vicente", Estudios portugueses, París, 1974, p. 26.

$2_{24}^{4}$ L. Stegagino-Picchio, História do Teatro Português, Lisboa, 1969, p. 28. 252.

${ }^{25}$ H. López Morales, "Alfonso X y el teatro medieval castellano", RFE, LXXI (1991), pp. 227- 
Otro tanto puede decirse de los xogos desonestos que se ejecutan en el interior del templo. No será muy aventurado pensar que se refieran a aquellas festae stultorum, festae asinorum o "fiestas del obispillo", que, celebradas durante el mes de Diciembre (concretamente el 6 si la realizaban los estudiantes y el 26 si eran los cantores de las catedrales), y protagonizadas por los niños del coro y los subdiáconos, parodiaban e invertían las ceremonias litúrgicas y las jerarquías eclesiásticas; al menos eso es lo que parece indicar la prohibición del sinodal de Oporto ya referido en el que se prescribe que en los días cercanos a Navidad no se hagan jogos no coro na igreja. Aunque tales espectáculos gozaron de gran intensidad en toda la Península, lo cierto es que el testimonio más temprano que hemos localizado relativo a la celebración de la fiesta en la zona geográfica estudiada se sitúa en una fecha tardía y es el de la Catedral de Oviedo de finales del XVI, donde la práctica se continúa hasta bien entrado el XVII ${ }^{26}$.

\subsection{El Corpus}

Los acontecimientos espectaculares que se han seleccionado para esta ponencia se inscriben en la celebración de la fiesta del Corpus y ambos se insertan en un sistema simbólico de representación que ocupa el espacio urbano y en el que, como veremos, los polos opuestos de lo sagrado y profano se unen en el ritual procesional.

Como se sabe, la festividad del Corpus (que asimiló los rituales paganos del antiguo solsticio de verano) fue instituida por el papa Urbano IV en 1264 y a su celebración se le confirió carácter obligatorio en el Concilio General de Vienne en 1311 (siendo papa Clemente V). Será Juan XXII el que ordene en el año 1316 que la fiesta se conmemore con procesiones eucarísticas en toda la cristiandad. Aunque en la parte oriental de la Península se documentan tempranamente las pompas de la celebración (Gerona 1314, Barcelona 1319, Vich 1330, Valencia 1355, Mallorca 1371), para Castilla, Galicia y Portugal los datos que se tienen son de fechas bastante posteriores, pues ninguno es anterior a los primeros años del siglo XV (Murcia 1419, Sevilla 1454; Valladolid 1498; Alcobaça 1435, etc.).

Habida cuenta de que era la única celebración litúrgica del año en que el propio Cuerpo de Cristo traspasaba los límites del templo y ocupaba el espacio urbano, éste se preparó para tan solemne acto poniendo en marcha toda una maquinaria espectacular en la se sobreponen materiales decorativos diversos: estandartes, banderas, danzas, escenas vivientes (en un libro de cuentas del monasterio de $45-47$

26 J. Menéndez Peláez, El teatro en Asturias. (De la Edad Media al siglo XVIII), Gijón, 1981, pp. 
Alcobaça figura la compra de máscaras, pelucas, barbas, diademas, una llave para el que ha de representar a S. Pedro, etc. $)^{27}$, el alfombrado de flores de las calles por las que ha de pasar la custodia, música, antorchas, fuegos artificiales etc. Con la fiesta, por tanto, la ciudad se modifica, se llena de convenciones particulares y la comunicación visual y auditiva adquieren un papel de primer orden.

La organización y los gastos de tal actividad correrán a cargo de los tres grandes centros de poder de las villas y ciudades: el poder eclesiástico (con el Cabildo al frente), el político (representado en el Concejo) y el mercantil (que actúa a través de los gremios). Además de decidir el orden en el que desfilarían las cofradías (generalmente, y por lo que se deduce de un consistorio fechado en Santiago el 23 de mayo de 1567 ( $f^{\circ} 235$ ), se hacía en función de la antigüedad de la constitución del gremio; naturalmente los lugares principales estaban reservados para la Virgen y para el patrón o patrona de la ciudad), cada una de las instituciones debía disponer una serie de órdenes para los miembros de su estamento en particular (así, por ejemplo, el doc. 28 correspondiente al año 1602 del legago 68 del Archivo de Pontevedra en el que el Justicia y Regimiento de la villa conmina a llegar a tiempo con las imágenes e insignias, no hacer revueltas, sacarse los sombreros de la cabeza, no hacer ruidos ni alboroto so pena de excomunión; o, incluso, el Consistorio de Santiago de 1576 $\left(\mathrm{f}^{\circ}\right.$ 66v) en el que se obliga a las cofradías de los respectivos gremios a presentarse a las 7 de la mañana frente al Ayuntamiento "para que sean vistos por los dichos señores cómo van y que se cumple lo que se les manda", ya que el año anterior "unos oficios llegaron y salieron con la procesión y otros al medio y otros al cabo".).

Nuestra atención se detendrá concretamente en dos elementos de la Procesión que, por sus rasgos particulares y por conservarse aún hoy en día en localidades aisladas de Galicia y Portugal, requieren un análisis detallado: se trata de la Coca y las Penlas ${ }^{28}$.

\subsubsection{La Coca}

Con este nombre, proveniente de un latín tardío *cocatrix (que Du Cange recoge y del que subraya su utilización en la Península Ibérica), se denomina al monstruo fantástico que iba en la procesión del Corpus, llevado por el gremio de los zapateros, y que en otras partes se denomina Patum (Berga) o Taras$c a$, "la sierpe contrahecha que suelen sacar en algunas fiestas y regocixos", según las palabras de Covarrubias ${ }^{29}$. Esta última designación encuentra su pro-

${ }^{27}$ Los datos son proporcionados por M. MARTins, "O Teatro Litúrgico na Idade Media Peninsular", en Estudos de Cultura Medieval, Lisboa, 1969, p. 24.

${ }_{2 x}$ Un breve y acertado panorama histórico de ambos elementos espectaculares puede verse en Cl. Gonzáazz Perez, As penlas e a danza de espadas, Vigo, 1987, y del mismo A. Coca, Vigo, 1987.

${ }^{24}$ S. DE Covarrubias, Tesoro de la lengua castellana o española, edición preparada por M. de Riquer, Barcelona, 1943. 
bable explicación en un topónimo: provendría de la ciudad de la antigua Provenza Tarascón, donde, según cuenta la leyenda, existía un horrible dragón en el Ródano que tenía aterrorizada a la población, hasta que fue vencido por santa Marta, a quien se atribuye la evangelización de la zona. Esta narración de carácter fabuloso fue recogida en una de las colecciones de vidas de santos que gozó de más popularidad a lo largo de la Edad Media, la Flos Sanctorum o Legenda aurea del dominico Iacopo de Voragine (ca 1230-1298) — y cabe recordar aquí que santos que vencen a animales maléficos y que cuentan con una leyenda parecida a la de Santa Marta son varios; a título de ejemplo pueden citarse entre otros los casos de S. Jorge, S. Miguel, Sta. Margarita, Sta. Marina, etc-. El texto del arzobispo de Génova fue traducido a casi todas las lenguas romances y su influencia deja sentirse especialmente en la traducción gallega del Codex Calixtinus, los conocidos Miragres de Santiago, cuya fecha de composición se sitúa a finales del siglo XIV ${ }^{30}$.

La representación diabólica en un monstruo hundía sus raíces en los propios textos bíblicos. Sin necesidad de recurrir al tan conocido episodio del Génesis, ¿cómo no tener presentes al poderoso Leviatán del Libro de Job (40 y 41) o la lucha del arcángel San Miguel con el dragón "rojo, de siete cabezas y diez cuernos", descrita por San Juan en el Apocalipsis? La procesión del Corpus constituía una oportunidad magnífica para escenificar la lucha entre el bien y el mal y encauzar hacia terreno cristiano una figura grotesca que daba la oportunidad al público de conectar con la ceremonia mediante un elemento espectacular, que se inscribe perfectamente en la cultura carnavalesca de la Edad Media postulada por M. Bahktine: una vez más DOCERE y DELECTARE se daban la mano a través de un elemento tradicional que era aprovechado con un significado simbólico en la fecha del antiguo solsticio de verano.

Aunque se sabe que tal manifestación popular recorrió las calles de Orense, Santiago, Betanzos, Pontevedra, Coimbra, Oporto, Braga, etc., lo cierto es que hoy sólo se conserva en la localidad gallega de Redondela y en la portuguesa de Monçao (a escasos kilómetros de la frontera con Tuy). En unos sitios el monstruo es vencido por San Jorge - cuya fama se había extendido por todo el Occidente europeo a raíz de la I Cruzada, concretamente a partir del año 1098, fecha de la caída de Antioquía, donde se decía que el santo había aparecido para ayudar a los cruzados, y, sobre todo, a raíz de una leyenda hagiográfica de los primeros años del siglo XIII, que contaba que había vencido a un enorme reptil en Libia- y en otros por mozos del gremio de los mareantes, que danzan con espadas y que obligan a que el antagonista se rinda.

La primera documentación que tenemos de la participación del monstruo en la Procesión se encuentra en una disposición del obispo de Orense del año 1437, que permite deducir que la coquetriz del gremio de los zapateros-que

\footnotetext{
${ }^{30}$ Miragres de Santiago, edición y estudio crítico por J. L. PENSADO, Madrid, 1958.
} 
es el encargado de transportarla en todos los lugares- es un elemento con cierta tradición (segundo que ha acostumado):

"Esta he a ordenança e regra que ordenaron o señor obispo con acordo dos juises et rejedores da çibdade d'Ourense que se fesese en día do Corpo de Deus das confrarías da dita çibdade. As quaes ordenaron en esta maneira que se sige:

Iten, primeiramente, que a confraría dos carniçeiros con seu touro que ande de diante con seus ofiçios, segundo que an acostumado.

Iten, que ande logo a terçeira confraría depús os carniçeiros, a confraría de San Migeel, que son os ferreiros, con seus ofiçios, segundo que an acostumado.

Iten, que ande logo a terçeira confraría depús la de San Migeel, a confraría de Santa Oufémea, que he dos çapateiros, con seus ofiçios et coquetriz, segundo que ha acostumado"31.

Más interesante es la disposición fechada en 1451 y de la que seleccionamos el siguiente pasaje:

"Iten, que a confraría de Santa Oufémea, por quanto era antígoamente feita e hordenada, ela e a dita confraría de Santa María Madre ante que as outras confrarías nehuas e o corpo da Virgen Santa Oufémea estaba sopultado ena dita sua ygllesia e por seu onor e do seu corpo, que ende está sopultado, que ordenaba e mandaba que andase logo a dita confraría de Santa Oufémea depúus a confraría de Santa María Madre con sua danza de espadas e çirios e outros jogos algúus, se os tebesen, salvo que o jogo da qoqa que andase aalende das confrarías de San Sebastián e de San Migeel, junto con a confraría dos carniçeyros, por que a dita coqa he escandallosa" 32 .

El texto vuelve a dar cuenta de las revueltas que se ocasionaban entre las cofradías por ocupar el lugar más adelantado posible en la procesión, pero además nos informa que la Coca debe circular alejada del gremio encargado de llevarla "por que a dita coqa he escandallosa"; se le asigna el último lugar, junto a la cofradía de la pecadora arrepentida (María Magdalena), al lado del toro de los carniceros. Desconocemos qué tipo de escándalos ocasionaba la Coca en el siglo XV, pero sí eran los mismos que tienen lugar durante los siglos XVIII, XIX y parte del XX está más que justificado su alejamiento de la divina custodia: niños y jóvenes que le tiran piedras, insultos a las personas que la llevan, los mozos que iban dentro sacaban de vez en cuando los brazos por la boca del dragón y cogían todo lo que podían de los puestos de los vendedores ${ }^{33}$,

${ }^{31}$ Texto extraído de X. Ferro Couselo, A vida e a fala dos devanceiros. Escolma de documentos en galego dos séculos XIII ao XVI, Vigo, 1967, p. 117.

32 Idem Ibídem, p. 145.

${ }^{33}$ Cfr. la información proporcionada por P. PÉREz COSTANTI en Viejas notas galicianas, Vigo, 1926, vol. II, pp. 95 y ss. 
es decir, lo suficiente como para entender que hoy en día esté totalmente desconectada de la procesión.

La desaparición de la Coca en Galicia se debió en gran medida a la publicación de la real cédula de 20 febrero de 1777, en la que Carlos III ordenaba que quedaban totalmente prohibidos "disciplinantes, empalados, ni otros espectáculos semejantes que no sirvan de edificación, y pueden servir a la indevoción y al desorden de las procesiones de Semana Santa, Cruz de Mayo, rogativas y algunas otras". El 21 de julio de 1780 vuelve a publicarse otra prohibición por parte del rey en la que se hace mención explícita de la Tarasca: "fui servido mandar se quitasen y cesasen en Madrid para lo sucesivo los Gigantones, Gigantillas y Tarasca (...) pues solo servian para aumentar el desorden y distraer o resfriar la Devoción de la Magestad Divina..."34.

Según apuntan algunos archivos municipales como el de Pontevedra o Santiago, la prohibición fue bien acogida por los gremios que veían en la ley la forma de dejar de ser el blanco de las bromas del público, a la vez que conseguían librarse de los gastos económicos que causaba la preparación del espectáculo. Así lo hace notar un documento del Archivo Municipal de Pontevedra que dice:

"y digo que por abuso y costumbre malamente introducida se ha puesto al cargo y cuidado de los antecesores de mis partes como del Gremio de dicha Cofradía el sacar y destinar un sujeto que en la Procesión del Corpus Christi y su octava llevase en su delantera por las calles públicas una figura irrisible, dándole el nombre de Tarasca a lo que se les estrechava por dicha justicia con el fribolo pretexto de estar en costumbre, y para evitar esta molestia noticiosas mis partes de lo preceptuado por S.M. (Dios le guarde) en su Real Orden expedida en febrero del año pasado de 1777 por la que se prescribe que todas las Justicias del Reino no permitan en sus respectivas jurisdicciones semejantes espectáculos, o fantasmas irrisibles, que impiden la devoción y fervor de los fieles cristianos, y aun dar con ello motivo a varios desordenes en las procesiones tan serias y misteriosas como aquella, y otras a que se agregan los excesivos gastos que por esta razon sufren los mayordomos y aun el mismo gremio en detrimento de sus mismas casas y familia, se lo han representado mis partes en los 8 de abril pasado deste año a dicha justicia y regimiento de la referida villa por pedimiento que al asunto le han presentado, a fin de que teniendo presente lo prevenido en dicha Real Orden, y los gastos y molestias que en ello se les ocasionaba les eximiese de tan fastidiosa y perjudicial costumbre, abuso y corruptela, no han podido conseguir decreto alguno..."35.

De todas las Cocas que hubo tan sólo se conservan las de Monção y Redondela, que han pasado por encima de todas las prohibiciones y dificulta-

\footnotetext{
${ }^{34} \mathrm{Cfr}$. el texto de las reales cédulas en C. C. Garcí VALDés, El teatro en Oviedo 1498-1700 a través de los documentos del Ayuntamiento y del Principado, Oviedo, 1983, p. 105.

${ }^{35}$ Archivo Municipal de Pontevedra, Legajo 68/60, 12 de junio de 1783.
} 
des, contándose hoy como una de las manifestaciones tradicionales de mayor esplendor en la fiesta del Corpus.

\subsubsection{As Penlas}

Con esta palabra de etimología incierta (para unos proviene de un diminutivo de PILA 'pelota', de la que derivaría la voz antigua 'pella' y la expresión "traer como a pelia" con el significado de 'zarandear', mientras que para otros tendría su origen en un deverbal de PENDERE, 'estar suspendido, colgado'o en un diminutivo de PENNA, 'pluma'), se hace referencia a una de las danzas que acompaña la procesión del Corpus, hoy sólo en Redondela, pero que, a finales de la Edad Media, se documentaba en otras partes de Galicia y Portugal.

Desconocemos cómo eran antiguamente, pero la práctica no podía diferir mucho de la que se realizaba en el siglo pasado y que continúa en la actualidad. Dos niñas pequeñas - de entre seis a ocho años- son llevadas en la procesión a hombros de mujeres fuertes a las que se denomina Burras, que las sujetan por medio de unos finos aros atados a la cintura de la penla. Obedeciendo a los movimientos de la mujer, que sigue la música de la gaita, el tambor y las castañuelas (tocadas por los mozos que realizan la danza de espadas), las niñas ejecutan diversos movimientos y contorsiones a lo largo de toda la procesión, como si estuviesen haciendo reverencias al Santísimo. Teniendo en cuenta el esfuerzo que exige la ejecución del baile no extraña que en algún documento haya peticiones de relevo por señalar la mujer que "está baldada de los brazos" 36 . Por lo menos hasta el siglo XVIII hacían su primer pase dentro de la Iglesia, justo antes de salir la procesión, pero los testimonios contemporáneos aluden ya sólo a la danza en el espacio urbano.

Es de todos conocido que desde los primeros siglos del Cristianismo fueron prohibidos aquellos "turpia cantica et saltationes" que se realizaban en el templo so pretexto de celebrar las grandes fiestas, pero en los que la iglesia no veía más que el peligro del lenguaje gestual y de viejas costumbres paganas. Una de las primeras referencias peninsulares se encuentra en el III Concilio de Toledo (589), al que asisten el rey Recaredo y el arzobispo Leandro, y en el que se utiliza el verbo exterminar para esas costumbres que sólo perturban el "divinal oficio". Pero la diligencia de las autoridades eclesiásticas no debió surtir los efectos deseados, porque las mismas prohibiciones vuelven a repetirse machaconamente diez siglos más tarde, concretamente en el Concilio Provincial de Aranda de 1473 y en el de Sevilla de 1512.

La primera referencia que conocemos de las penlas se encuentra en la Chrónica de el-rei don João I (1383-1433) de Fernao Lopes (ca. 1380-1459), el cronista de la batalla de Aljubarrota (1385), que cuenta precisamente que

${ }^{36}$ Cfr., por ejemplo, el del Archivo Municipal de Pontevedra, Legajo 68/36, 31 de mayo de 1954. 
con ocasión de la celebración de la batalla sobre los castellanos, cuando el rey entró en Oporto:

"A mesteiraaes e muyta outra gente eram emcomendadas damças (e) jogos doutras maneiras, em que amdavom velhos e mancebos, todos com leda vomtade. As molheres jsso mesmo em seu bando fezerom pellas muyto bem corregidas, as quaaes acompanhavom com muytas cantigas, dellas feitas em louvor del Rey e outras acostumadas, nom soomente as de meaao estado e comdiçam, mas muytas das bõoas da çidade amdavom com ellas por homra da festa"37.

De la cita precedente parece extraerse que el baile popular se ejecutaba en otras conmemoraciones que no fuesen las estrictamente religiosas. En Galicia el primer documento en que ya aparecen unidas a la celebración "do Corpo de Deus" procede de Santiago de Compostela y data del año 1565 (si bien referencias de tipo genérico a las danzas ejecutadas por los gremios ya se encuentran en el Consistorio del 10 mayo de $1532, \mathrm{f}^{\circ} 35 \mathrm{r}$ ):

"y a los tecelanes, lleben una dança de romeros y romeras; y los carniceros lleven una fulía portuguesa; y los horneros lleben sus pelas muy bien aderesçadas; y los oficios que suelen llebar figuras las lleben asimesmo. Y cada uno de los dichos oficios agan las dichas danças e regocixo el dicho día de Corpus Cristi, y los mayordomos e bicarios las agan hazer a costa de los dichos oficios e lo cumplan so pena de cada dos mill maravedises e veynte días de cárcel al que lo contrario hiciere..." 38 .

Al igual que en otras localidades el gremio encargado de ejecutarlas es el de los panaderos, que era el que contaba con el mayor número de mujeres (a pesar de que el texto no es explícito a cerca de si son hombres o mujeres), porque, según referencias tardías (entre las que cabe citar al P. Sarmiento ${ }^{39}$ ), era la corporación que trabajaba con el pan, es decir, con el elemento que se consagra en la misa, con el propio Corpus Christi.

En 1598 se fecha la referencia a las penlas de Pontevedra y aquí sí se dice que las ejecutantes son mujeres, que son recompensadas por el Concejo con una donación de harina (a las mugeres a quien estan repartidas las penlas trinta libras, son dos del pan de trigo, María Estévez y Catalina Suárez, mujer de Xoan da Vila, tecelán, y del pan de centeno María del Rossal y Catalina Castaña, y a cada dos se an de dar quince libras $)^{40}$.

\footnotetext{
${ }^{37}$ FERNÃo Lopes, Cronica del Rei Dom Joham I de bõa memoria e dos Reis de Portugal o decimo, ed. de W. J. Entwistle, Lisboa, 1977, cap. IX, p. 18.

${ }^{34}$ El texto procede de P. Pérez Costanti, Notas viejas galicianas, Vigo, 1926, tomo II, p. 86.

${ }^{39}$ Fr. Martín Sarmiento, Colección de voces y frases gallegas, edición y estudio de J. L. Pensado, Salamanca, 1970, p. 118.

40) Archivo Municipal de Pontevedra, Legajo 69/1, 18 de mayo de 1598.
} 
Una de las primeras prohibiciones de la danza se encuentra asimismo en el Archivo Municipal de Pontevedra y está fechada en mayo de 1606 (legajo 68, doc. 29); se trata de una carta del arzobispo de Santiago Maximiliano de Austria dirigida a las autoridades de la villa en la que dice que "ansimesmo que no saliessen las penlas en la procesion por ser cossa yndecente...". De todas formas sus palabras cayeron más bien en saco roto, porque documentos de años posteriores ( 2 de julio 1652 , doc. $35 ; 31$ de mayo de 1654, doc. 36 ; doc. 40 , 1674; doc 43, 1675, etc) confirman la vigencia de las penlas.

En la desaparición del baile desempeñó un papel muy importante la cédula de Carlos III, a la que ya se ha hecho referencia a propósito de la Coca, así como motivos económicos, ya que la preparación del espectáculo generaba gastos onerosos en las corporaciones. Esta último circunstancia la corrobora una petición del gremio de los marineros de Pontevedra ante las autoridades civiles de la villa para no tener que salir con su nave el día de la fiesta: previniendo se suspenda tal gasto, como V. S. lo tiene practicado con las Penlas, Danza de Espadas... ${ }^{41}$.

Los datos hasta aquí proporcionados indican que tanto la Coca como las penlas eran manifestaciones tradicionales que la Iglesia permitió añadir a la celebración del Corpus, divinizándolos (incluso, a veces, virilizándolos) y confiriéndoles el sentido simbólico de la adoración a Cristo. Ambos espectáculos ofrecían la ventaja de trasponer el discurso religioso en un lenguaje visual comprensible para todas las clases sociales. Al fin y al cabo, las autoridades eclesiásticas sabían que, para captar público, era más útil dirigirse al pueblo con el miramiento que con la retórica de la palabra.

${ }^{41}$ Archivo Municipal de Pontevedra, Legajo 68, documento 69. 